\title{
Variations of phase velocity and gradient values of ULF geomagnetic disturbances connected with the Izu strong earthquakes
}

\author{
V. S. Ismaguilov ${ }^{1}$, Yu. A. Kopytenko ${ }^{1}$, K. Hattori ${ }^{2}$, and M. Hayakawa ${ }^{3}$ \\ ${ }^{1} \mathrm{SPbF}$ IZMIRAN, St.-Petersburg, Russia \\ ${ }^{2}$ RIKEN IFREQ, MBRC Chiba University, Chiba, Japan \\ ${ }^{3}$ UEC, Chofu, Japan
}

Received: 30 May 2002 - Accepted: 19 August 2002

\begin{abstract}
Results of study of anomaly behavior of amplitudes, phase velocities and gradients of ULF electromagnetic disturbances $(F=0.002-0.5 \mathrm{~Hz})$ before and during a seismic active period are presented. Investigations were carried out in Japan (Izu and Chiba peninsulas) by two groups of magnetic stations spaced apart at a distance $\sim 140 \mathrm{~km}$. Every group (magnetic gradientometer) consists of three 3component high sensitive magnetic stations arranged in a triangle and spaced apart at distance 4-7 km. Kakioka magnetic station ( $>200 \mathrm{~km}$ to the North from Izu) was used as a reference point. Available data (only night-time intervals 00:00-07:00 LT) were preliminary filtrated by narrow passband filters (16 frequency bands - periods $T=2-512 \mathrm{~s}$ ). The amplitude, gradient and phase velocity values and probabilities of directions of gradient and phase velocity vectors were constructed for the every frequency band. Apparent resistivities of the Earth's crust in the every frequency band were calculated using the phase velocity values. It was found that $Z$ component amplitudes of the ULF magnetic disturbances increased at Izu peninsula 2-4 weeks before the seismic active period and 2-4 days before the strongest seismic shocks $(M>6)$. Ratio of $Z$ component amplitudes of Kamo (Izu) and Kakioka data $\left(Z_{k} / Z_{k k}\right)$ increased during 2-4 weeks before the seismic activity start (27 June 2000) and reached a maximum just before a moment of the strongest seismic shock (EQ with $M=6.4$ ). The gradient and the phase velocity values had an anomaly behavior during the same 2-4 weeks before the start of seismic active period. The gradient vectors of the total horizontal component of the ULF magnetic pulsations were probably directed to the regions with increased conductivity. New additional direction of the gradient vectors appeared 2-3 weeks before the seismic activity start - the direction to the seismic active area which appeared due to a magma rising.
\end{abstract}

Correspondence to: Yu. A. Kopytenko

(galina@gh5667.spb.edu)

\section{Introduction}

In previous works it was found that two kinds of ULF EM disturbances connected with EQ origin zone: (1) a direct radiation from EQ origin zone (Kopytenko et al., 1990, 1993; Fraser-Smith et al., 1990; Bernardy, et al., 1991; Molchanov et al., 1992; Ismaguilov et al., 2001) and (2) a changing of electric conductivity inside and nearby the EQ hearth zone leads to changing of amplitudes of reflected electromagnetic waves generated by outer sources (Mogi, 1985; Kovtun, 1980; Gasanenko, 1963; Ismaguilov et al., 2001; Kopytenko et al., 2002).

In this paper we continue to study an anomaly behavior of amplitudes, gradients and phase velocities of ULF EM disturbances before and during a seismic active period. Seismic shocks started 27 June 2000 and lasted more then 4 months. EQ epicenters were situated at a distance $\sim 70-90 \mathrm{~km}$ to the southeast from Izu peninsula (Japan) under a sea bottom. The strongest seismic shock $(M=6.4)$ was observed 01 July 2000 at 16:01:56 LT.

A method of constructing of the gradient and phase velocity vectors along the Earth's surface using three-point measurements of the ULF magnetic field variations was described in (Kopytenko et al., 2000; Ismaguilov et al., 2001; Kopytenko et al., 2002). The phase-gradient method gives a possibility to find a direction to the ULF EM ionosphere and lithosphere sources and to determine a position of future seismic activity regions, if the ULF EM disturbances are connected with these regions. Three magnetic stations situated one from the other at small distances are the ULF magnetic radar.

\section{Experiment}

Measurements of ULF EM fields were performed by two groups of magnetic stations spaced $\sim 140 \mathrm{~km}$ apart. The every group consists of three MVC-2DS high sensitive threecomponent torsion magnetometers (Goto et al., 2002) with 


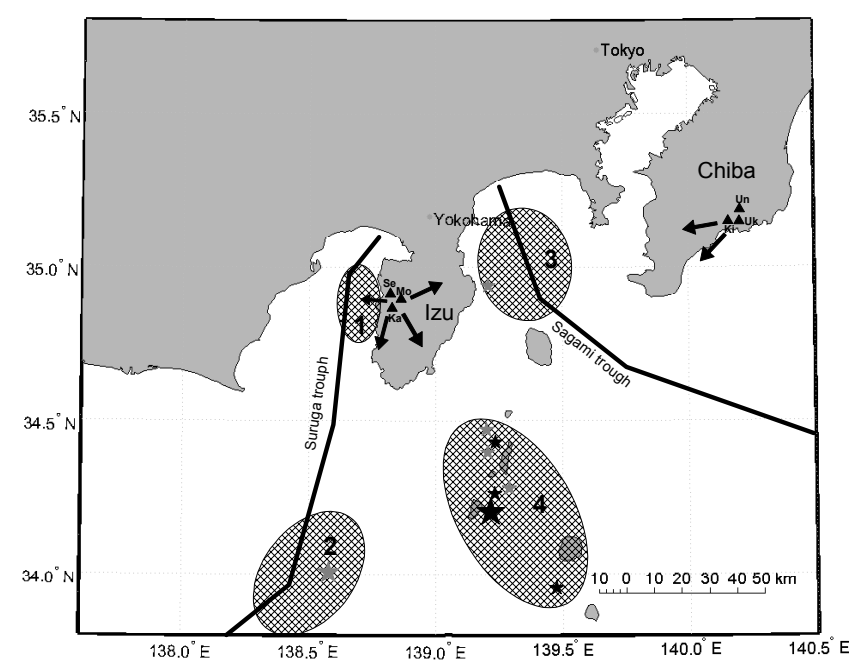

Fig. 1. Positions of geoelectric anomalies around Izu peninsula (Japan) defined by the phase-gradient method. 1 - "seashore effect" zone; 2, 3- regions with increased conductivity where EQ had occurred in recent years (gray stars - positions of strongest EQ); 4 - seismic activity region (black stars - positions of latest EQ with $M \geq 6$ ). Small black triangles - magnetic stations. Black arrows directions of gradients of ULF magnetic pulsations.

$50 \mathrm{~Hz}$ sampling (Kamo $-12.5 \mathrm{~Hz}$ ) arranged in a triangle and spaced $\sim 4-7 \mathrm{~km}$ apart. GPS systems were used at every station for data synchronization. One group of the magnetometers was installed at Izu peninsula (Seikoshi, Mochikoshi and Kamo), another one - at Chiba peninsula (Unobe, Kiyosumi and Uchiura). Positions of the magnetic stations and epicenters of the seismic shocks with magnitude $M \geq 6$ are shown at the Fig. 1. Black stars mark the epicenters. The strongest shock (EQ) had the magnitude $M=6.4$. The biggest black star at the Fig. 1 marks this epicenter. The epicenter of this EQ was situated at a depth $\sim 15 \mathrm{~km}$ under a sea surface at a distance $\sim 80 \mathrm{~km}$ to the southeast from the magnetic stations located at Izu peninsula and $\sim 140 \mathrm{~km}$ to the southwest from the magnetic stations located at Chiba peninsula.

\section{Data processing and experimental results}

Only nighttime intervals 00:00-07:00 LT were used for data processing because of too big man-made EM noise during daytime at Japan territory. Available data were preliminary filtrated by narrow pass-band filters (17 frequency bands periods $2,3,4,8,12,16,24,32,48,64,96,128,192$, $256,384,512 \mathrm{~s})$. High frequency of data acquisition and using of GPS receivers on the each of magnetic stations allow building vectors of the gradient and the phase velocity of the ULF geomagnetic disturbances $(F=0.002-1 \mathrm{~Hz}$ ) along the Earth's surface. The amplitude, gradient and the phase velocity values and probabilities of directions of gradient and velocity vectors were constructed for the every frequency band.

For low-frequency waves $(w<1 \mathrm{~Hz})$ the wave equations, obtained from the Maxwell equations, are reduced to the dif- fusion equations (Semenov, 1968). For a harmonic source $\left(B \sim e^{-i w t}\right)$ the diffusion equations have a partial solution for the magnetic field variations (Jeffreys and Swirles, 1966) in one-dimensional case (real part):

$$
\boldsymbol{B}=\boldsymbol{B}_{0} e^{-\boldsymbol{k} x} \cos (\boldsymbol{w} t-\boldsymbol{k} x) \text {. }
$$

Here $\boldsymbol{k}=2 \pi / \lambda=\left(\boldsymbol{w} \mu_{0} / \rho_{a}\right)^{1 / 2}, t$ - time, $\boldsymbol{B}_{0}$ - initial amplitude, $\rho_{a}$ - apparent resistivity. Let's remark, that in the low frequency limit the wave equation with a big accuracy has the same partial solution for the plane waves (Semenov, 1968). Therefore $\boldsymbol{k}$ has a wave vector sense, and $\boldsymbol{\lambda}$ is a wavelength. At the diffusion approach we can speak about a moving non-uniformity of induction currents having a wave character.

The phase velocity along the Earth's surface of the primary EM wave falling down from the atmosphere is $\geq \boldsymbol{c}$ (the light velocity) and a phase delay between two points at the Earth's surface is very close to 0 . Therefore the phase delays of the EM waves observed at the Earth's surface are completely determined by the secondary EM waves reflected or generated by the lithosphere sources (geoelectric anomalies of conductivity situated in the Earth's crust or sources connected with the EQ preparation region) and propagated in the Earth's crust. From (1) it is possible to determine a velocity of moving plane of a constant phase (the phase velocity $\boldsymbol{V}_{p h}$ ) and the apparent resistivity $\boldsymbol{\rho}_{a}$ of the Earth media (integrated value along the EM wave track):

$$
\begin{gathered}
\boldsymbol{V}_{p h}=\boldsymbol{w} / \boldsymbol{k}=\left(2 \boldsymbol{\rho}_{a} \boldsymbol{w} / \mu_{0}\right)^{1 / 2}=\left(10^{7} \boldsymbol{\rho}_{a} / \boldsymbol{T}\right)^{1 / 2} \\
\boldsymbol{\rho}_{a}=10^{-7} \boldsymbol{V}_{p h}^{2} \boldsymbol{T} .
\end{gathered}
$$

Here $\boldsymbol{T}=1 / \boldsymbol{f}=2 \pi / \boldsymbol{w}-$ period of oscillations, $\mu_{0}=$ $4 \pi \cdot 10^{-7} N / A^{2}-$ absolute magnetic constant (we suppose that relative magnetic constant $\mu=1$ in the Earth's crust). Therefore, if the phase velocity of the wave propagation in the Earth's crust is known, we can find the apparent resistivity of the Earth's crust along the way of the EM wave from a lithosphere source to the Earth's surface. We apply a statistical study and use mean values of the phase velocities calculated for some time interval.

An example of a time evolution of various parameters of the geomagnetic pulsations with period $\boldsymbol{T}=24 \mathrm{~s}$ before and during of the seismic active period is shown in Fig. 2. Only nighttime intervals 00:00-07:00 LT were used for data processing. Points at the figure (panels $b-h$ ) are mean values calculated for these time intervals. To delete occasional jumps in the results three-point running means were used for curves represented in the Fig. 2. Vertical dotted lines at the Fig. 2 mark the start of the seismic activity (27 June 2000) and moments of the seismic shocks with magnitudes $M>6$. Magnitudes of the seismic shocks (vertical lines) are shown according to JMA classification at the panel a. The strongest EQs happened on 2 July $2000(\mathrm{M}=6.4), 09.07(M=6.1)$ and on 15 July $2000(M=6.3)$.

Time evolutions of ratios of mean-square amplitudes of the vertical $(\boldsymbol{Z})$ and the total horizontal $(\boldsymbol{G})$ component of Kamo (k) and Kakioka (kk) data $(\boldsymbol{T}=24 \mathrm{~s})$ are plotted at 


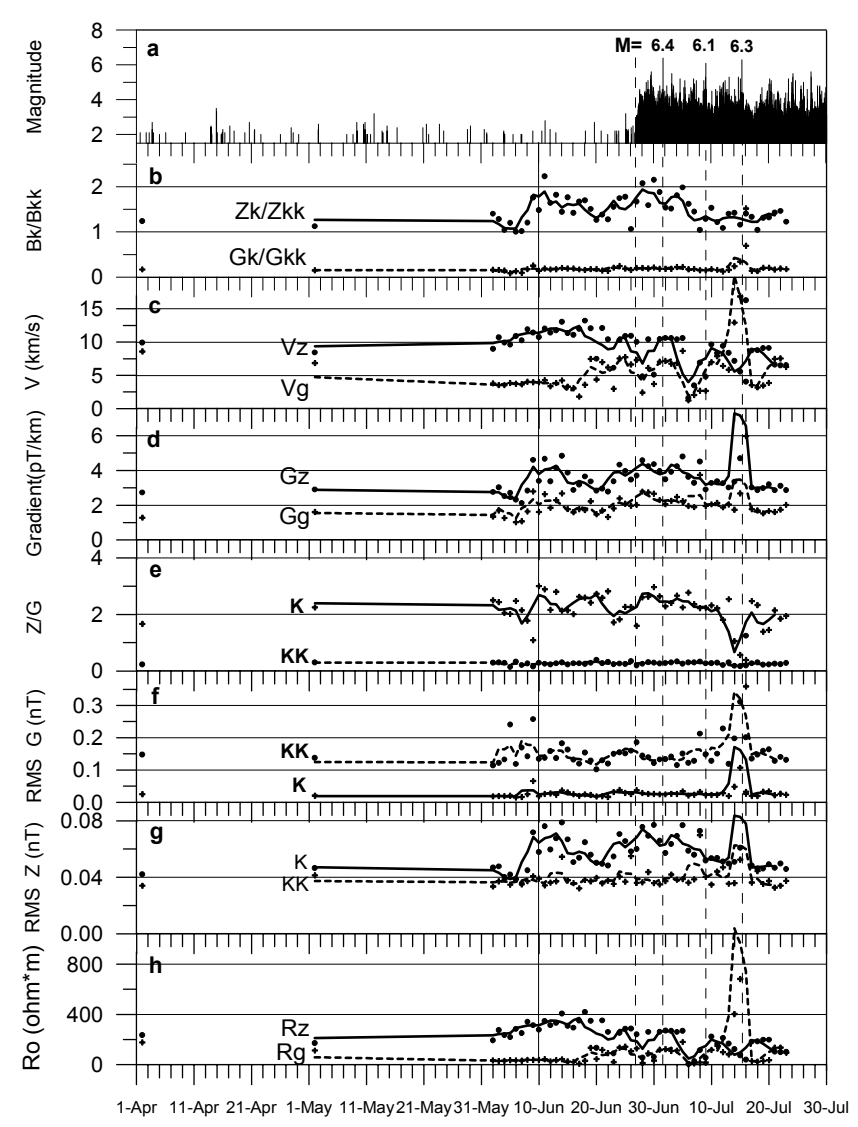

Fig. 2. Variations of parameters of geomagnetic pulsations $(\boldsymbol{T}=$ $24 \mathrm{~s}$ ) during period 1 April - 25 July 2000 (nighttime intervals 00:00-07:00 LT). Kakioka, Kamo, Seikoshi and Mochikoshi magnetic stations (Japan). (a) magnitudes of seismic shocks (vertical lines) according to JMA classification; (b) ratios of mean-square amplitudes of the vertical $(Z)$ and the total horizontal $(G)$ component of Kamo (K) and Kakioka (KK) data; (c) the phase velocities calculated at Izu peninsula for the vertical (solid line) and the total horizontal (dotted line) component; (d) the gradients calculated at Izu peninsula for the vertical (solid line) and the total horizontal (dotted line) component; (e) $Z / G$ ratios for Kamo (K) and Kakioka (KK) data; (f) RMS values of amplitudes of the total horizontal component for Kamo (K) and Kakioka (KK) data; (g) RMS values of amplitudes of the vertical component for Kamo (K) and Kakioka (KK) data; (h) the apparent resistivities calculated at Izu peninsula from the phase velocity values for the vertical (dotted line) and the total horizontal (solid line) components. All curves are 3-points running means.

the panel (b) of the Fig. 2. It is clearly seen that the ratio of $\boldsymbol{Z}$ magnetic component amplitudes of Kamo (Izu) and Kakioka data $\left(\boldsymbol{Z}_{k} / \boldsymbol{Z}_{k k}\right)$ increased during 2-3 weeks before the seismic activity start (26 June 2000) and reached second maximum 28-30 June 2000 just before the moment of the strongest seismic shock $(M=6.4)$. It means that the ULF pulsation amplitudes of $Z$ component were anomaly increased at Kamo magnetic station relatively Kakioka. This effect is more clearly seen for the longest ULF pulsation periods $96-512 \mathrm{~s}$ (not presented in this paper), moreover the sec-

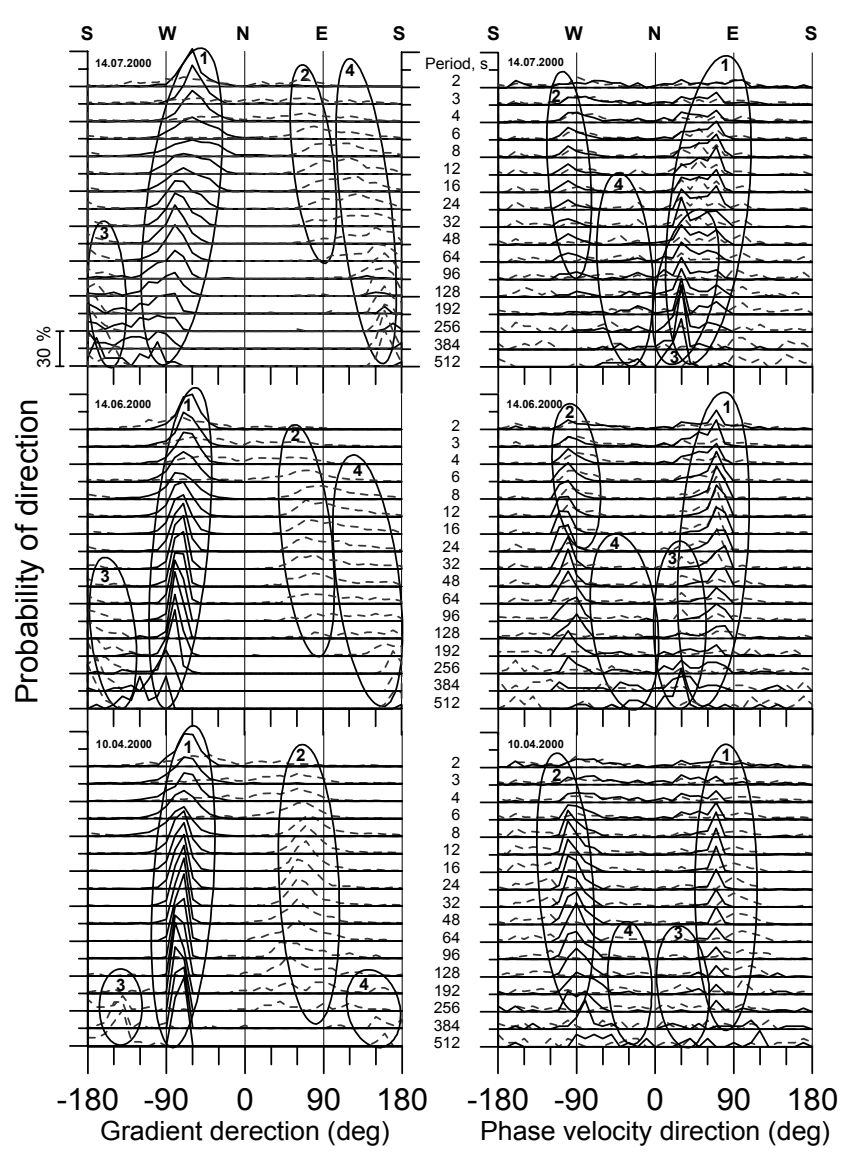

Fig. 3. Statistical distributions of gradient (left side) and phase velocity (right side) vector directions of total horizontal component of ULF geomagnetic disturbances 01.05 (dotted curves), 08.06 (thick solid curves), and 10 July 2000 (thin solid curves) in period range 2-512 s. Izu peninsula, Japan. 1-4 - directions to the anomaly regions plotted in Fig. 1 . Directions: $0^{\circ}-$ to the North, $90^{\circ}-$ to the East, $-90^{\circ}-$ to the West, $180^{\circ}$ and $-180^{\circ}-$ to the South.

ond maximum value exceeds a background level (defined by $\boldsymbol{Z}_{k} / \boldsymbol{Z}_{k k}$ values of 01.04 and 1 May 2000) in 2-3 times. There is no noticeable effect in the total horizontal component ratio $\boldsymbol{G}_{k} / \boldsymbol{G}_{k k}$. Some increasing of this ratio about 15-16 June 2000 is probably connected with the very strong magnetic storm.

Values of the phase velocities calculated at Izu peninsula using all three magnetic station data for the vertical (dotted line) and the total horizontal (solid line) component are presented at the panel $\mathrm{c}$ of the Fig. 2. The phase velocity and gradient vectors were calculated in according to (Kopytenko et al., 2000; Ismaguilov et al., 2001; Kopytenko et al., 2002) only for events when a coefficient of correlation between data of every couple of Izu magnetic stations exceeds a value 0.9. We see from the Fig. 2 that the phase velocity of magnetic pulsations in $Z$ component slightly increased 2-4 weeks before the beginning of the seismic active period and then it decreased. We can observe minima of the phase velocity before the seismic activity start and before the every strong EQ. The phase velocity of the magnetic pulsations in the total hori- 
zontal component increased about two weeks before the start of the seismic shocks. It had similar time evolution as the phase velocity obtained for the vertical component.

The gradient values of ULF geomagnetic pulsations calculated at Izu peninsula for the vertical (dotted line) and the total horizontal (solid line) component are plotted at the panel (d). Both curves have a similar time evolution. Increasing of the gradients was observed 2-3 weeks before the seismic shocks start. Second maximum occurred 4-5 days before the strongest EQ. A sharp increasing about 15 July 2000 was probably connected with the strong magnetic storm. Statistical distributions of the gradient vector directions are represented in Fig. 3.

The traditional $\boldsymbol{Z} / \boldsymbol{G}$ ratios for Kamo $(\mathrm{K})$ and Kakioka (KK) data submitted in the panel (e). There are some features connected with the seismic activity in $24 \mathrm{~s}$ geomagnetic pulsations. For the lower frequency band $(\boldsymbol{T} \sim 100 \mathrm{~s})$ distinct increasing of $\boldsymbol{Z} / \boldsymbol{G}$ ratios 2-4 weeks before the seismic activity start were observed for this seismic event (Ismaguilov et al., 2001; Kopytenko et al., 2002) and also for another seismic events (Hayakawa et al., 1996a, b; Hattori et al., 2002). A sharp decreasing of $\boldsymbol{Z} / \boldsymbol{G}$ ratios about 15 July 2000 is probably connected with the strong magnetic storm.

Time evolution of RMS values of amplitudes of the total horizontal component for Kamo (K) and Kakioka (KK) data and for the vertical component for Kamo $(\mathrm{K})$ and Kakioka (KK) data are represented at the panel (f) and (g). A sharp distinction is seen in variations of $Z$ component of Kamo and Kakioka. We observe again the maximums 2-4 weeks before the start of the seismic active period and 2-4 days before the strongest EQ. A big increasing about 15 July 2000 was probably connected with the big magnetic storm.

The apparent resistivities calculated at Izu peninsula according to Eq. (2) from the phase velocity values of the vertical $\left(\boldsymbol{V}_{z}\right.$, solid line) and the total horizontal $\left(\boldsymbol{V}_{g}\right.$, dotted line $)$ components are shown at the panel (h) of the Fig. 2. The apparent resistivity values calculated from $\boldsymbol{V}_{z}$ values increased 3-4 weeks before the seismic activity start then they constantly decreased. 2-4 days before the every strong seismic shock we observe minimums of the apparent resistivity values. The apparent resistivities values calculated using $\boldsymbol{V}_{g}$ values had the same wavy character as the apparent resistivities calculated from $\boldsymbol{V}_{z}$ values. The sharp increasing observed about 15 July 2000 was probably connected with the big magnetic storm.

\section{Discussion and summary}

In this work we demonstrate that many parameters of the ULF geomagnetic pulsations (amplitudes, gradients and phase velocities along the Earth' surface) have an anomaly behavior 2-4 weeks before the beginning of the seismic activity and 2-4 days before the strongest seismic shocks. Comparison of the Kamo and Kakioka data (Fig. 2) shows that the magnetic devices installed at distance $\sim 80 \mathrm{~km}$ from the future seismic active area can record ULF magnetic dis- turbances really connected with the seismic preparation region.

Estimations of the apparent resistivity values calculated from the phase velocity values differ from the estimations calculated from the impedance values. Magneto telluric sounding method (MTS) uses the values of electric and magnetic horizontal components of the ULF EM pulsations and gives the apparent resistivities integrated in the Earth's media under a point of observation. The phase-gradient method gives the apparent resistivities integrated along the way of the EM waves propagated from the secondary sources situated in the Earth's crust. The new source can arise in the Earth's crust due to active tectonic movements or a magma rising (Uyeda et al., 2002). During these processes a temperature and conductivity of some region in the Earth's crust around the future EQ origin zone will increase (Bullard, 1967) and conditions for reflecting of the EM waves penetrating in the Earth's crust from the atmosphere will improve.

Two circumstances lead to a big changing of the apparent resistivity calculated from the phase velocity values. On the one hand we can receive the changing of the apparent resistivity because new ways of the EM wave propagation throw the Earth's crust arise. The new ways are in the Earth's crust with the resistivity that differs from the resistivity of the old ways. On the second hand the value of the phase velocity of the geomagnetic oscillations measured along the Earth's surface (we use in Eq. (2) just these values) is connected with the value of the phase velocity in the Earth's crust by a formula $\boldsymbol{V}_{\text {surface }}=\boldsymbol{V}_{\text {Earth }} / \sin (\alpha)$, where $\alpha-$ angle of the wave arrival to the surface from the lithosphere source counted from a vertical. The new EM wave tracks lead to changing of the angle $\alpha$ and accordingly to changing of the phase velocity and the apparent resistivity calculated using this method. Therefore the phase-gradient method gives an opportunity to determine a moment of arising or changing of the ULF EM lithosphere source in a local anomaly zone.

In Fig. 3 statistical distributions of the gradient (left side) and the phase velocity (right side) directions presented for three days: 10.04 (bottom curves), 14.06 (middle curves), and 14 July 2000 (upper curves) in the pulsation period range $2-512 \mathrm{~s}$. The gradient vectors were calculated using RMS values and they are always directed to the sources. Ovals 14 in Fig. 3 mark the directions to the regions with geoelectric anomalies marked in Fig. 1 by the same symbols $1-4$. It is seen from the figure that 10 April $2000(\sim 10$ weeks before the seismic activity start) and 14 July 2000 (during the seismic activity) new directions of the gradient vectors arise the direction to the seismic active region where the anomaly occurs. The anomaly of the conductivity appeared due to the magma rising (Uyeda et al., 2002). The resistivity of the hot magma is $\sim 500 \mathrm{Ohm} . \mathrm{m}$, but the granite electrical resistivity, for instance, exceed $1000 \mathrm{Ohm} . \mathrm{m}$.

The phase-gradient method described in (Kopytenko et al., 2000, 2002; Ismaguilov et al., 2001) is very sensitive to the changing of properties of the lithosphere ULF sources.

Acknowledgement. This work was partly supported by Grant IN- 
TAS 99-1102.

\section{References}

Bullard, E. C.: Electromagnetic induction in the Earth, Q. J. Roy. Astron. Soc., 8, 143-160, 1967.

Bernardy, A., Fraser-Smith, A. C., McGill, P. R., and Villard, Jr., O. G.: ULF magnetic field measurements near the epicenter of the $M_{S}=7.1$ Loma Prieta earthquake, Phys. Earth. Planet. Inter., 68, 45-64, 1991.

Fraser-Smith, A. C., Bernardy, A., McGill P. R., Ladd, M. E., Helliwell, R. A., and Villard, Jr., O. G.: Low frequency magnetic field measurements near the epicenter of the Loma-Prieta earthquake, Geophys. Res. Lett., 17, 1465-1468, 1990.

Gasanenko, L. B.: Impedance of ULF direct line current field situated above Earth, in: Electromagnetic sounding and magnetotelluric methods of exploring, St.-Petersburg, Leningrad University, (in Russian), 47-58, 1963.

Goto, T.-N., Sayanagi, K., and Mikada, H.: Calibration and running test of torsion magnetometer made in Russia, Rep. Of Japan Marin Sci. and Tech. Center (JAMSTEC), 45, 41-53, 2002.

Hattori, K., Akinaga, Y., Hayakawa, M., Nagao, T., and Uyeda, S.: ULF magnetic anomaly preciding the 1997 Kagoshima earthquakes, in: Seismo Electromagnetics: Litosphere-AtmosphereIonosphere Coupling, (Eds) Hayakawa, M. and Molchanov, O. A., TERRAPUB, Tokyo, 19-28, 2002.

Hayakawa, M., Kawate, R., Molchanov, O. A., and Yumoto, K.: Results of Ultra-low-frequency magnetic field measurements during the Guam earthquake of 8 August 1993, Geophys. Res. Lett., N23, 241-244, 1996a.

Hayakawa, M., Kawate, R., and Molchanov, O. A.: Ultra-lowfrequency Signatures of the Guam Earthquake on 8 August 1993 and their Implication, J. Atm. Electr., 16, 3, 193-198, 1996 b.

Ismaguilov, V. S., Kopytenko, Yu. A., Hattori, K., Voronov, P. M., Molchanov, O. A., and Hayakawa, M.: ULF magnetic emissions connected with under sea bottom earthquakes, Nat. Hazards and Earth Sys. Sci., 1, 23-31, 2001.

Jeffreys, H. and Swirles, B.: Methods of mathematical physics, Third Edition, Cambridge Univ. Press, Cambridge, 157, 1966.

Kopytenko, Yu. A., Matiashvily, T. G., Voronov, P. M., Kopy- tenko, E. A., and Molchanov, O. A.: Discovering of ultra-lowfrequency emissions connected with Spitak earthquake and his aftershock activity on data of geomagnetic pulsations observations at Dusheti and Vardzija, Moscow, IZMIRAN, Preprint N3 (888), 27, 1990.

Kopytenko, Yu. A., Matiashvili, T. G., Voronov, P. M., Kopytenko, E. A., and Molchanov, O. A.: Detection of Ultra-Low Frequency emissions connected with the Spitak Earthquake and its aftershock activity, based on geomagnetic pulsations data at Dusheti and Vardzia observatories, Phys. Earth and Planet. Inter., 77, 8595, 1993.

Kopytenko, Yu. A., Ismaguilov, V. S., Kopytenko, E. A., Voronov, P. M., and Zaitsev, D. B.: Magnetic location of geomagnetic disturbance sources, DAN, series "Geophysics", 371, 5, 685-687, 2000.

Kopytenko, Yu. A., Ismaguilov, V. S., Hattori, K., Voronov, P. M., Hayakawa, M., Molchanov, O. A., Kopytenko, E. A., and Zaitsev, D. B.: Monitoring of the ULF electromagnetic disturbances at the station network before EQ in seismic zones of Izu and Chiba peninsulas, in: Seismo Electromagnetics: LitosphereAtmosphere-Ionosphere Coupling, (Eds) Hayakawa, M. and Molchanov, O. A., TERRAPUB, Tokyo, 11-18, 2002.

Kovtun, A. A.: Using of natural electromagnetic field of the Earth under studying of Earth's electroconductivity. St.-Petersburg, Leningrad University, (in Russian), 195, 1980.

Mogi, K.: Earthquake prediction., Academic Press, Tokyo, 382, 1985.

Molchanov, O. A., Kopytenko, Yu. A., Voronov, P. M., Kopytenko, E. A., Matiashvili, T. G., Fraser-Smith, A. C., and Bernardy, A.: Results of ULF magnetic field measurements near the epicenters of the Spitak $\left(M_{S}=6.9\right)$ and the Loma-Prieta $\left(M_{S}=7.1\right)$ earthuakes: Comparative analysis, Geophys. Res. Lett., 19, 14951498, 1992.

Semenov, A. A.: Theory of electromagnetic waves, Moscow Univ. Press, Moscow, (in Russian), 316, 1968.

Uyeda, S., Hayakawa, M., Nagao, T., Molchanov, O., Hattori, K., Orihara, Y., Gotoh, K., Akinaga, Y., and Tanaka, H.: Electric and magnetic phenomena observed before the volcano-seismic activity in 2000 in the Izu Island Region, Japan, Proc. of US Nat. Acad. of Sci., 99, 11, 7352-7355, 2002. 